\title{
Cross-Cultural Understanding for Global Sustainability: Messages and Meanings from Asian Cultural Landscapes
}

\author{
Prof. Dr. Rana P.B. Singh, M.A., Ph.D., J.F.F., F.A.A.I., F.A.C.L.A. \\ Vice-President: ACLA - Asian Cultural Landscape Association \\ Head, Department of Geography, Faculty of Science, Banaras Hindu University, \\ \& Professor of Cultural Geography \& Heritage Studies, \\ Cell: +091-9838 119474. Fax: +091-2368010. Email: ranapbs@gmail.com
}

Keywords: understanding tradition, global sustainability, Cultural landscapes, sacredscapes, heritage ecology, imbued meaning, reflective aesthetics

\begin{abstract}
Concept of 'multifunctionality' of cultural landscapes is a reflection of imbued meaning and aesthetics inherent there and also human manifestation of this spirit through existence and aliveness by human creation, love and continuance in various cultures and traditions. This sense helps envisioning landscapes that cross urban-rural divides in sustainable and an integrated way - characterised by wholeness and ecospirituality that developed in the cultural history of landscape sustainability. That is how, the idea of 'wholeness' (cosmality) is transformed into 'holiness' (sacrality) - evolved and represented with sacred ecology and visualised through the cosmic frames of sacredscapes in Asian region that survived there as part of lifeworld. Understanding, feeling, living with, practicing and passing on these inherent meanings and aesthetics provide peace, solace and deeper feelings to human mind which are the ethereal breathe of sustainability. The rethinking should be based on the foundational value - the reasoning that underlies the ethical sense of deeper understanding of Man-Nature Interrelatedness, the basic philosophy of coexistence - referred in different cultures in their own ways, like multicultural co-living ('Old-comer') in Korea, harmonious coexistence (tabunka kyosei) in Japan, harmonious society (xiaokang) in China, wahi tapu (sacred places) in Maori's New Zealand, global family (vasudhaiva kutumbakam) in Indian thought, and also African humanism (ubuntu) in South Africa. Think universally, see globally, behave regionally, act locally but insightfully; this is an appeal for shared wisdom for global sustainability in making our cultural landscapes mosaic of happy, peaceful and sustainable places crossing all the borders and transitions, especially interwoven links among Korea, Japan, China, and India.
\end{abstract}

\section{Cultural Landscapes: The Perspectives}

Concept of 'multifunctionality' of cultural landscape can help envisioning landscapes that cross urban-rural divides in sustainable and an integrated way - characterised by wholeness and ecospirituality that developed in the cultural history of landscapes. That is how, the idea of 'wholeness' (cosmality) is transformed into 'holiness' (sacrality) - evolved and represented with sacred ecology and visualised through the cosmic frames of sacredscapes in Asia-Pacific region. In the era of cybernetic, it becomes a global concern to understand and re-revealed the grounds of shared wisdom among various cultures where in spite of all the changes, the inherent roots and instinct spirits are still lie in their roots.
Virtually all landscapes have cultural associations, because virtually all landscapes have been affected in some way by human action or perception. Therefore, the phrase "cultural landscape" does not mean a special type of landscape; instead, it reflects upon a way of seeing landscapes and associated attributes that emphasizes the interaction between human beings and nature over time - maintaining existencecontinuity-transformation and transferability that makes the cultural landscape ecology exposed and practiced in the purview of lifeways and lifeworlds. The cultural landscape is an object of change either by the development of a culture or by a replacement of cultures through human interfaces, interaction and reciprocity. The datum line from which changes are measured is the natural condition of the landscape that has a primordial instinct. As resultant, cultural 
landscape shows influences worked on people by their institutions, taboos, design preferences, built-up architecture, and system and spatial order, assemblages of cultural features which comprise their cultural landscape, and which support and embrace their civilisations - that is how cultural landscape is conceived as an integral part of ecological cosmology.

Difference or distinctiveness is not deficiency; so-to-say diversity is not divergence. Interaction, reciprocity and symbiosis between natural sciences and humanities, which are designed to synthesize and integrate diverse perspectives, are crucial for deeper understanding. That is how landscape ecology (or architecture) can gain much from transdisciplinary collaborations with social sciences such as cultural geography and design sciences such as landscape architecture and engineering. A stronger emphasis on the cultural dimension will make landscape ecology even more relevant to sustainability (Wu 2010:1149).

\section{Axioms for Reading the Sacredscape}

The following basic and self-evident rules (axioms) are posited by Lewis (1979: 15-26) for reading the landscape which in modified (in Indian context) form are useful in reading the sacredscape:

1. The Sacredscape is clue to culture. The human impingement trusted upon and cognized by the devotees provide strong evidence of the kind of human culture we possess in the past, preserving in the present, and would continue in the future. In other words, they refer to our processes of becomingness. How in the historical past for their own sake and imitation human being searched the sacred power of place while mytholising them and making them alive through ritualisation process. These activities later converge into a religious tradition.

2. The Sacredscape refers to cultural unity and place equality. All the items and aspects in the sacredscape are no more and no less important than other items in terms of their role as clues to cultural tradition. Sacred journey and circumambulation are as equally important a cultural symbol as the territorial extension, and changes in people's attitudes and behaviours show the process of "existence-maintenance-transformation-andadaptation." This finally converges to make a whole - a unity - that is how sacredscapes become holy.

\section{The common features of Sacredscapes possess} the intrinsic meaning. Whatever we see by a common eye is only the outside appearance; however there also lies invisible intrinsic meaning which would be understood only through the faith and deeper feelings in the cultural context. At super-shrine it is believed that religious activity embraces both worlds, with no distinction drawn between the pragmatic and the transcendent.

4. For the Sacredscape history matters. Says Lewis (1979: 22): "That is, we do what we do, and make what we make because our doings and our makings are inherited from the past." The sacredscapes are the cultural heritage resource where history matters. The symbolism, mythology, ritualisation process and the ultimate faithscape evolved - all are the subject to the historical process of transformation and human adaptation, therefore they need special care.

\section{The Sacredscapes make little sense if out from} sacred ecology. Human psyche and manifestive power in the sacredscape are the basic elements for making it existent and continue. They have specific location interpreted in a broader context of symbolism and where divine power is perceived by human being in transcendental form of consciousness. They replicate the macrocosm on the earth as mesocosm which is further revealed at the level of microcosm (human mind and faith, or an individual shrine or temple).

\section{The messages conveyed by Sacredscapes are} obscure but communicates. As the human psyche varies from one to another, local to regional, and the "messages" conveyed are so varied that making broad generalization is not possible. For understanding and analysis several set of questions be put before into the habit of asking them simply by doing so: What does it look like? How does it work? Who designed it? Why? When? What does it tell us about the way our society and culture work? To understand the message, one has to 
be a part of the pilgrimage itself as a pilgrim, avoiding completely looking like a pilgrim.

The literary evidences show that the ancient Chinese philosophy of "unity of man with nature" and its associated design principles can provide useful guidelines for reciprocity and integrating man and nature that lead to the development of a sustainable landscape architecture. Of course, there appear several regional and sub-cultural visions of Chinese rural cultural landscapes and representing architectures, the three most common and basic framework include "unity of man with nature" or "harmony between man and nature" philosophy, "peach blossom spring" ideal, "world-in-a-pot" model, and Feng-shui theory, and their implications for developing a sustainable landscape architecture (Chen and $\mathrm{Wu}$ 2009: 1015). This theme is consistent with the central tenet of Taoism, a celebrated Chinese philosophy developed by Lao $\mathrm{Zi}$, which asserts that humans should harmonize with the rhythms of nature. Harmonious coexistence between humanity and nature, as a background assumption, has been epitomized in the principles guiding Chinese landscape architecture since its origin. The Chinese philosophy and archetypal construct of mannature interrelatedness is close to Indian foundation, of course with different ways of narrations (cf. Fig. 1). The Indian thought goes back to at least first century BCE, i.e. the Vedic period, and deals exhaustively about maintenance of order between man and nature through the principles of harmonious reciprocity and interrelatedness (rita). In both, Chinese and Indian thoughts "the pot model", "peach blooming", moral imperatives, "Five-Elements" (pancha-mahabhutas), and "eight trigram" (asta dika), "Feng-Shui" (Vastu-purusha) are close to identical expositions.

The Chinese five-element doctrine (Fengshui), guided by the Yin-Yang principle, claims that the material world is composed of five kinds of elements (metal, wood, water, fire, and earth), all of which are related to each other by either a creating-being created relationship or a controlbeing controlled relationship. This is close to Indian five gross elements (pancha-mahabhutas) doctrine that deals with combinations and ordering among the five elements (space, air, water, fire, and earth. The Korean Pung-su is identical to Chinese Feng-shui, as both of the principles of landscapes refer to breath of life (prana in India, $k i$ in Korea, ch'i in China), and closely related to wind and water.

Fig. 1. China and India: Philosophical and cultural foundations of the landscape architecture

China

(after Chen and Wu 2009: 1017).

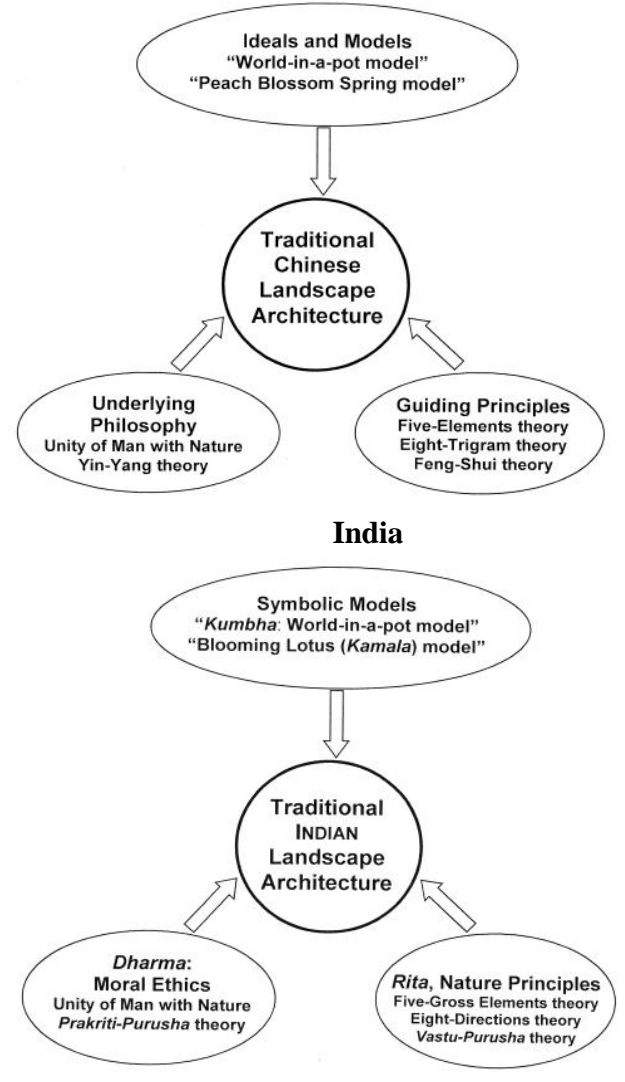

These ideas have been explained in terms of Eum (Yin)-Yang, and Five Elements theory. The basic theory of Pung-su in Korea, in fact, came from ancient China, but Koreans have modified it that befit into their own system. To understand the theory behind Pung-su, it is necessary to understand early Chinese philosophy, which says basically that all things and events of the world are products of two elements, Eum (Yin) and Yang. Chou Tun-i, one of the founders of Neo-Confucianism, in his book, An Explanation of the Diagram of the Great Ultimate (T'ai-Chi T'u-shuo) summarized the doctrine of Yin-Yang and the Five Elements that "By the transformation of yang and its union with yin, the Five Agents of Water, Fire, Wood, Metal, and Earth arise. 
Fig. 2. A Conceptual framework for a sustainable Chinese Landscape Architecture (LA) and parallel of Sustainability Science (SS) [after Chen and Wu 2009: 9].

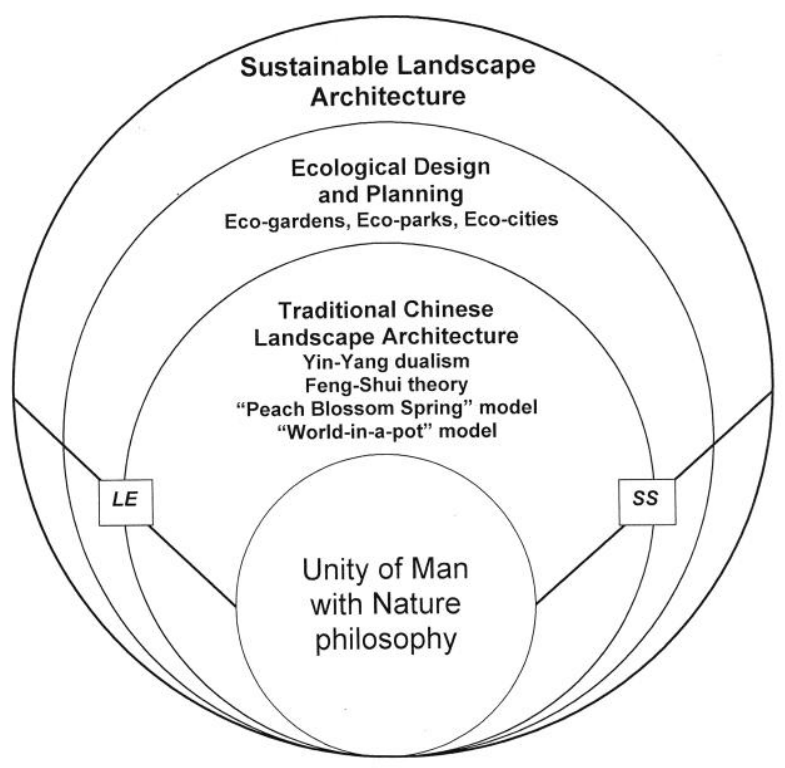

To improve the contemporary situation and also to make applicable to whole of Asia, and so to whole world, Chen and $\mathrm{Wu}$ (2009: 9) have proposed a conceptual framework for a sustainable Chinese landscape architecture that is built on the philosophy of Unity of Man with Nature and Chinese landscape and architectural traditions, which also incorporates the principles and methods of landscape ecology (LE) and sustainability science (SS) (cf. Fig. 2). It is felt that sustainable landscapes are more likely to be developed and maintained if the three pillars of sustainability - environment, economy, and society - are simultaneously considered. Musacchio (2009) discussed six elements of landscape sustainability (or six $\boldsymbol{E}$ 's): environment, economy, equity, aesthetics, ethics, and (human) experience - all together to be taken as network and interlinkage in making cultural landscape sustainable and happy habitat.

\section{Interlinkage: Shared Vision - Man- Nature interrelatedness and Sustainability}

Broad and more popularly, three broad groups of qualities are used for evaluating landscapes: natural (ecological valuable, geologically distinct, or known for rich flora and fauna), cultural (expression of human imprint, or creative art forms), and aesthetic (panoramic view or landmarks. In different countries these are categorised and characterised by the cultural acceptance and legal jurisdictions. In historical and national contexts, different meanings are also inscribed. In the above context three basic meanings, in historical context, to the understanding of cultural landscapes, viz. (i) a political meaning - to assure responsibility for the decisions, (ii) a cultural meaning - to save culture rootedness and sense of continuity, and (iii) a didactic meaning - to promote citizen's participation.

Taking issues of maintenance of values, existence-and-continuity, structural transformation, appraising vitality and overall sustainability for the future, and all the other resultant and auxiliary issues are relevant at different levels and at varying degrees according to contextuality, regional personality and rational of demands. In the purview of Chinese landscape and its ecological imperative, set-theory is used to explain the interactions, reciprocity and overall "integrative habitat (rural-Urban) ecosystem" between bio-ecologic and socio-ecologic perspectives, which together makes "cultural landscape perspective". The two sets (Natures: bio-ecologic forms, and Cultures: socio-economic ways) in a way get superimposed that many be better emphasised in the visions and approaches of interdisciplinarity and transdisciplinarity (Fig. $3)$.

Fig. 3. Habitat ecology and its major characteristics (modified after Wu 2008: 44).

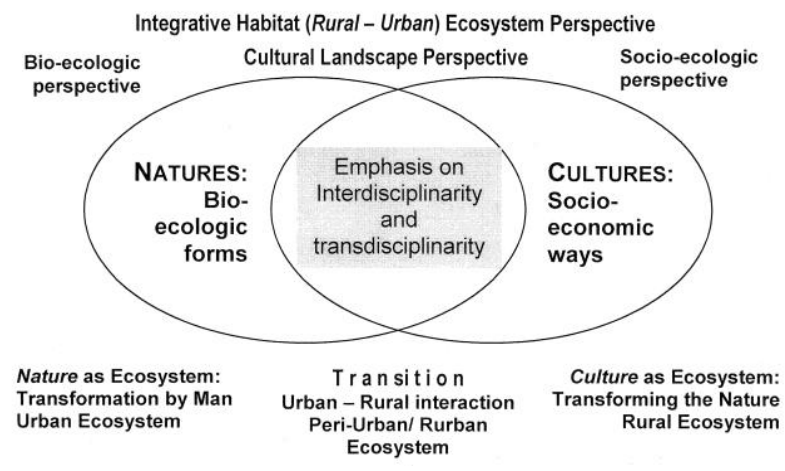

The bio-ecologic perspective views habitats (rural and urban settlements) as severely disturbed ecosystems and humans as disturbance agents, which adopts a biology-centred, basic science approach, and offers little interdisciplinarity between natural and social sciences. The socio-ecologic approach, on the 
other hand, views habitats as socioeconomic systems designed for human welfare, and tends to deemphasize the importance of biodiversity and ecosystem services, thus again discouraging cross-disciplinary interactions between natural and social sciences (cf. Fig. 3).

\section{The Vision}

Vision without Action is Empty. Action without Vision is Blind. Let the Vision be force behind Action, and Action the energy behind Vision. This is the way to understand the interconnectedness between human beings and the Mother Nature.

Let us keep the spirit always awakened and pray the Mother Nature (as landscape) to always direct us on the right path of realizing the sense of interconnectedness. This is a call for the nourishment of Soil, Soul and Society where the Humanity meets to the Divinity. Let us try to Understand it and Feel it, and ultimately get it framed in making 'sustainable landscapes'.

Fig. 4. Main constituent values of Sacred Natural Sites, SNS.

(after Verschuuren 2007: 308).

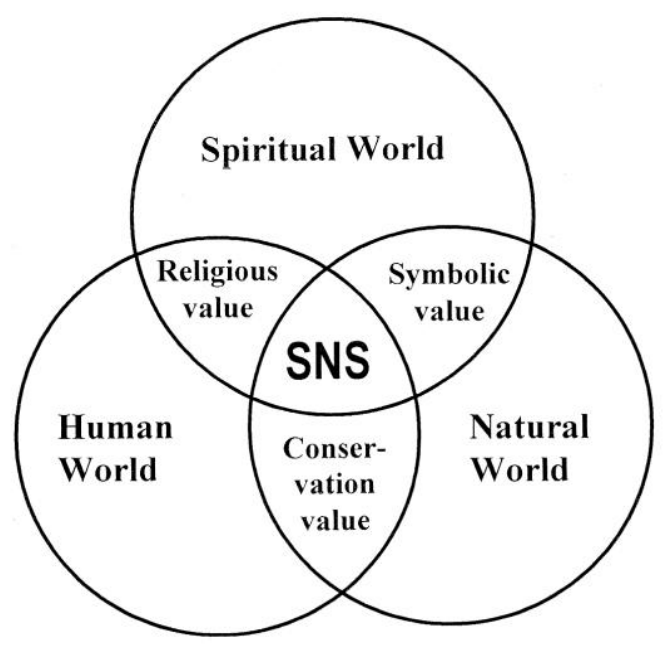

The most common view shared by institutionalised and indigenous spiritual traditions alike is that the world is a 'multiple level hierarchic reality', similar to that of Mircea Eliade's hierophany. These relationships may be represented with a simplified model showing three different planes that overlapping worldviews (cf. Fig. 4). Within these worldviews, different traditional cosmological sciences have evolved over time - often in harmony with nature - and many of which are still alive in different regions around the world (cf. Verschuuren 2007: 308). Remember what Devereux (1990: 216) said, "Let us hope we will have the sense to seek, the wisdom to listen, and the patience to learn".

\section{Walking on the path of Sacredscapes: Towards Destination}

The rethinking should be based on the foundational value - the reasoning that underlies the ethical sense of deeper understanding of ManNature Interrelatedness, which is the basic philosophy of coexistence - referred in different culture in their own ways, like harmonious coexistence (tabunka kyosei) in Japan, harmonious society (xiaokang) in China, multicultural co-living ('Old-comer') in Korea, wahi tapu (sacred places) in Māori's New Zealand, African humanism (ubuntu) in South Africa, and global family (vasudhaiva kutumbakam) in Indian thought. The ethical domain is based essentially on foundation value which for Gandhi was ahimsa (non violence), for Schweitzer reverence for life, and for Aldo Leopold the sacredness of land. Another vision from New Zealand, i.e. Mātauranga Māori refers to 'the knowledge, comprehension, or understanding of everything visible and invisible existing in the universe', and is often used synonymously with wisdom. Moreover, in the contemporary world, the definition is usually extended to include present-day, historic, local, and traditional knowledge; systems of knowledge transfer and storage; and the goals, aspirations and issues from an indigenous perspective. This altogether makes the holistic frame like cosmic integrity. Healing the Earth is the message of sacred ecology that envisions the interconnectedness between Man and Nature and further makes a way to environmental and cultural guardianship through making bridge linking realisation and revelation. This process of healing requires a specific mode of conduct or cultural consciousness, a religion - in fact a dharma, a moral duty (or to say like sacred duty, virtue that as human beingness one holds). The dharma of our culture is to save its sacred ecology promoting deeper moral values - the gateways of knowing the cosmic identity of human beings. Practicing sacred ecology is the "yoga of landscape" and the sacred journey to the symbol of earth spirit, i.e. heritage. 


\section{5 - 6 December 2013, Beijing, China}

Spirits permeate matter and animate it, so to say there generates the inherent force of terrestrial unity, what we call ecological cosmology. That is how the rich symbolic association brings the sacred as a life-force into everyday life. This permeates and encourages human sensitivity to march from realisation (anubhava in Sanskrit) to revelation (anubhuti in Sanskrit).

\section{References}

Chen, Xiangqiao and Wu, Jianguo 2009. Sustainable landscape architecture: implications of the Chinese philosophy of "unity of man with nature" and beyond. Landscape Ecology, 24: 1015-1026.

Devereux, Paul 1990. Places of Power. Blandford, London.

Lewis, Pierce F. 1979. Axioms for reading the landscape; in, Meinig, Donald W. (ed.) The Interpretation of Ordinary Landscapes. Oxford University Press, New York: 11-32.
Musacchio, Laura R. 2009. The ecology and culture of landscape sustainability: Emerging knowledge and innovation in landscape research and practice. Landscape Ecology, 24: 989-992.

Singh, Rana P.B. 2011. Indo-Kyosei Global Ordering: Gandhi's Vision, Harmonious Coexistence, \& Ecospirituality. Research Center for Kyosei Philosophy, Toyo University, Japan. Meitoku Publishing, Tokyo.

Verschuuren, Bas 2007. An overview of cultural and spiritual values in ecosystem management and conservation strategies; in, Haverkort, B. and Rist, S. (eds.) Endogenous Development and Bio-cultural Diversity, The Interplay of Worldviews, Globalisation and Locality. Compas/CDE, series on Worldviews and Sciences, No. 6, Leusden, The Netherlands: pp. 299-325.

Wu, Jianguo 2008. Making the case for landscape ecology: an effective approach to urban sustainability. Landscape Ecology, 27: 41-50.

Wu, Jianguo 2010. Landscape of culture and culture of landscape: does landscape ecology need culture? Landscape Ecology, 25: 1147-1150. 